Contributions may be in English, French or German.

Such a journal is to be welcomed, especially since a strong editorial board of zoologists, anatomists and embryologists has been appointed. It will no doubt relieve congestion in other journals, and will prove invaluable as a platform for discussion, especially among those scientific research workers interested in the rapidly advancing field of morphogenesisbiological, medical, veterinary, agricultural and so forth. British members of the editorial board include such authorities as M. Abercrombie, G. R. de Beer, J. D. Boyd, F. W. R. Brambell, Honor B. Fell, W. J. Hamilton, Sidnie M. Manton, P. B. Medawar, D. R. Newth, C. H. Waddington, J. Z. Young and S. Zuckerman. Other countries are represented on the board by the following: J. Brachet, A. Dalcq, J. Pasteels (Belgium); E. Fauré-Fremiet, Et. C. Wolff (France); J. Holtfreter (United States); S. Hörstadius (Sweden) ; F. E. Lehmann (Switzerland); Chr. P. Raven and M. W. Woerdeman (Holland); A. Stefanelli (Italy); S. Toivonen (Finland).

Papers in the first (March 1953) issue, which follow a foreword written by A. M. Dalcq in the form of an essay on development, are : J. Pasteels : "Les effets de la centrifugation sur la blastula et la jeune gastrula des Amphibiens. (1) Mécanisme de la formation des organes secondaires aux dépens de l'ectoblaste"; R. M. Clayton: "Distribution of Antigens in the Developing Newt Embryo"; H. V. Brøndsted : "Rate of Regeneration in Planarians after Starvation"; A. and H. V. Brøndsted: "The Acceleration of Regeneration in Starved Planarians by Ribonucleic Acid" ; Et. Wolff, K. Haffen, M. Kieny and Em. Wolff : "Essais de cultures in vitro d'organes embryonnaires en milieux synthétiques"; J. C. van de Kamer and A. J. Schuurmans : "Development and Structure of the Saccus Vasculosus of Scylliorhinus caniculus (L.)".

The editor of the Journal of Embryology and Experimental Morphogenesis is Michael Abercrombie, Department of Anatomy, University College, Gower Street, London, W.C.1, to whom all editorial communications should be sent.

\section{ATMOSPHERIC OZONE AND THE UPPER-AIR CONDITIONS}

$\mathrm{T}$ HE amount of ozone in the atmosphere is very small, amounting to a layer less than $3 \mathrm{~mm}$. thick at normal temperature and pressure. The ozone is nearly all in the stratosphere at heights between 20 and $40 \mathrm{~km}$. and is of great importance as it absorbs almost all the solar ultra-violet radiation. Dobson showed in 1929 that over Britain the total amount of ozone changed with the surface pressure distribution; the ozone amount was found to be high on the western sides of depressions and low over anticyclones. This relation did not hold everywhere, and it was suggested that the true connexion was with the state of the atmosphere at high levels rather than that near the ground.

The latest researches into the subject are clearly described by Sir Charles Normand in his 1952 presidential address to the Royal Meteorological Society, which has now been published (Quart. J. Roy. Met. Soc., 79, No. 339, $39 ;$ 1953). Observing at Oxford with the Dobson spectrophotometer, which permits observations of ozone amount to be made even when the sky is overcast with low cloud, he has found a close inverse correlation between ozone amount and the height of the $300-\mathrm{mb}$. isobaric surface, the thickness of the layer between 500 and $300 \mathrm{mb}$., and the height of the top of the troposphere-the tropopause. The connexion between them and ozone amount is very close, extending to variations taking less than a day to complete.

Besides reporting the result, Sir Charles discusses the origin. It was at one time thought that the relation between ozone and surface pressure distribution is due to horizontal motion of stratospheric air of high or low ozone content; but, though this may well be important during spring, when ozone increases from south to north, it cannot play a significant part during autumn, when there is very little latitudinal variation of ozone. Sir Charles sees the main reason for the relation between ozone amount and the meteorology of the upper troposphere in vertical motion in the stratosphere associated with rising or falling tropopause. As nearly all the ozone is in the stratosphere, it is clear that, provided formation and dissociation of ozone are sufficiently slow, convergence will bring about an increase in the total ozone content in a vertical column and divergence a decrease. Below $35 \mathrm{~km}$. the mass of ozone in a given mass of air (ozone mixing ratio) changes very slowly, and there is convergence in the stratosphere when the tropopause sinks.

Using available information on the vertical distribution of ozone, Sir Charles shows quantitatively that this explanation is reasonable. He looks forward to more accurate information in future both on the vertical and horizontal distributions of ozone which will make the result more definite. This information is expected from the observations of a network of Dobson spectrophotometers now being set up from Spitzbergen to the Azores and Spain under the auspices of the Ozone Commission of the International Union for Geodesy and Geophysics.

\section{DETERMINATION OF THE POSITION OF A RADIO STAR}

A PAPER entitled "The Determination of the Position of a Radio Star" by F. G. Smith (Mon. Not. Roy. Astro. Soc., 112, 5 ; 1952), describing work carried out as part of a programme of the radio research at the Cavendish Laboratory, Cambridge, gives a description of a number of new methods of using the spaced-aerial interferometer and compares their accuracies with those of older methods. Four of the possible methods are dealt with-the periodicity interferometer, the crossed-axis interferometer, the variable-axis interferometer and the double-transit interferometer-and each of these is examined in turn.

It is pointed out that the new methods are particularly applicable to the accurate determinations of the positions of intense radio stars; when the object of the observations is to detect the largest possible number of radio stars, the periodicity interferometer has advantages for declinations greater than about $30^{\circ}$, while the crossed-axis interferometer has advantages at lower declinations. Appreciable refraction may occur at radio wave-lengths in the troposphere and also in the ionosphere ; in the former the refraction makes the star appear nearer the zenith than it actually is, and as the refractive index of dry air is practically the same for radio waves as 
for light waves, the refraction effects correspond closely to the standard astronomical effects.

The refractive index of water vapour is greater at radio wave-lengths than at visual wavelengths, and hence appreciable deviations at large zenith angles may be caused by a rapid gradient of refractive index caused by a rapid lapse-rate of water vapour. This problem has been dealt with in the Physical and Meteorological Societies' Report (1947); a quotation from a publication shows the magnitude of the correction that is necessary. The total atmospheric refraction at an elevation of $5^{\circ}$ was ealculated to be $15^{\prime}$, one-third of which was due to water vapour. Irregular ionospheric diffractions occur and are accompanied by changes in the apparent position of the radio star, and this position may vary in a few seconds by $1-2^{\prime}$ of arc on a wave-length of $3.7 \mathrm{~m}$. In addition, regular ionospheric refraction takes place, and the simultaneous reception of radiation from two nearby stars may be responsible for confusion, the resulting error from which is discussed near the end of the paper.

\section{INSTITUTE OF PHYSICS ANNUAL GENERAL MEETING}

$\mathrm{A}^{\mathrm{T}}$

$\mathrm{T}$ the thirty-third annual general meeting of the Institute of Physics, held on May 29 at Bournemouth, during the second Convention of the Institute, the following were elected to take office on October 1: President, Dr. C. Sykes; Vice-President, Prof. F. A. Vick; Hon. Treasurer, Dr. S. Whitehead; Hon. Secretary, Dr. B. P. Dudding; New Ordinary Members of the Board, Mr. A. T. Pickles and Dr. P. S. H. Henry. Prof. A. M. Tyndall, a founder Fellow and pastpresident of the Institute, formerly professor of physics at the University of Bristol, and distinguished for his fundamental work on the mobility of ions and for his services to science and education, was elected to honorary fellowship of the Institute.

The thirty-third annual report of the Board, covering the work of the Institute during 1952, was adopted at the meeting. It records that the Board met six times, and its various standing committees twenty-three times, during the year. The membership increased by 267 to 4,357 ; but there were small decreases in the numbers of subscribers and student members. The total of those elected to grades of membership for which approved academic qualifications in physics are demanded was the highest since the foundation of the Institute. During the year, the first examination for the recently established graduateship grade took place; twenty-one candidates presented themselves and six satisfied the examiners. The annual report refers to the large increase in interest shown both by employers and colleagues in the National Certificates in Applied Physics. Some slight alterations in the regulations governing these Certificates have recently been made by the joint committee of the Ministry of Education and the Institute responsible for the award and control of the courses. In particular, a practical examination need no longer be held as part of the final assessed examination. For the 1952 examinations there were 137 candidates for the Ordinary and 33 for the Higher Certificate.

About half the work of the Institute is now devoted to its publications, and the magnitude and value of this work can be judged by the fact that receipts from sales, including advertisement revenue, were $£ 28,000$ during 1952. The circulation of both the Institute's journals, the Journal of Scientific Instruments and the British Journal of Applied Physics, continues to increase steadily. The amount of material submitted to the journals in 1952 was similar to that in 1951, but the number of special articles and reports in the Journal of Scientific Instruments was rather less than formerly, with more space devoted to original papers. Several new features were introduced into the monthly Bulletin circulated to all members; these include invited articles and an annual index. New volumes published during 1952 in the "Physics in Industry", series were "Industrial Magnetic Testing" by Prof. N. F. Astbury and "Metallurgical Equilibrium Diagrams" by Dr. W. Hume-Rothery, Mr. J. W. Christian and Mr. W. B. Pearson. Another interesting publication, "Physics as a Career", written by Mr. N. Clarke, deputy secretary of the Institute, at the suggestion of the Institute's Education Committee, is a guide to the available avenues of training leading to professional recognition as a physicist. A companion volume is the report, "The Scientific Education of Physicists", issued by the Education Committee. This contains details of the physics departments of all the universities and university colleges of Great Britain and of the technical colleges recognized by the Institute. An additional report entitled "Problems concerning the Education of Physicists" will be published shortly.

The Institute continues to be represented on many joint committees and bodies, including government committees and those of the Royal Society, the City and Guilds of London Institute and the British Standards Institution.

The fourth in the series of "Physics in Industry" conferences, and the first since the Second World War, was held in Glasgow during June 25-28, 1952. Its theme was "Physics in the Transport, Shipbuilding and Engineering Industries", and its object, as of those earlier in the series, was "to promote the application of physics to industry by bringing to the attention of industrial executive engineers and scientists recent developments in applied physics and by providing opportunities for the interchange of ideas with and among professional scientists". The conference was presided over by Sir Andrew McCance, and about four hundred people attended. Sir Andrew MaCance spoke on physics in the service of metallurgy ; Sir Robert Watson-Watt on meteorology in industry ; Prof. A.M. Robb on applications of physics in naval architecture; Mr. M. G. Bennett and Mr. T. A. Eames on applications of physics in transport ; Mr. A. J. Young on automatic control of industrial processes; and Mr. N. Fleming on noise and its suppression. Dr. D. T. N. Williamson gave a public address, with demonstrations, on physics and sound reproduction, and a discussion was held on the education and training of industrial physicists in Scotland. An exhibition of apparatus, instruments and books was held simultaneously at the Royal Technical College, Glasgow, and a catalogue of the exhibition and a handbook of the conference were published. The generous support of the catalogue by the exhibitors resulted in a handsome surplus of close on $£ 1,000$ being added to the Endowment Trust Fund of the Institute.

Details of the various activities of the sixteen local branches and specialist subject groups of the Institute are listed in the report. The Australian Branch held a four-day microscopy conference and exhibition in 